\title{
Working with Family, Friends, and Allies of LGBT Youth
}

\author{
Melissa Luke \\ Counseling and Human Services Department, Syracuse University \\ Kristopher M. Goodrich \\ Counselor Education, University of New Mexico
}

\begin{abstract}
As a historically marginalized population, lesbian, gay, bisexual, and transgender (LGBT) youth are at risk for myriad negative outcomes and as a result, seek counseling services at disproportionate rates. Although the role of family, friends, and allies (FFA) has been supported as a resiliency factor with LGBT youth, minimal attention has been given to the inclusion of FFA in counseling interventions. Building on the developmental, preventative, and wellness foundation, this manuscript utilizes an ecological approach to identify points of entry for systemic interventions with FFA across the micro, meso, exo, and macro levels (Bronfenbrenner, 2005) of LGBT youth experience.
\end{abstract}

Keywords: LGBT, ecological model, ally, counseling intervention, wellness, preventative model

The disproportionate risks and challenges faced by persons from and oppressed marginalized communities are well documented in the counseling literature (Hays, Dean, \& Chang, 2007; Okech \& Rubel, 2007; Sue \& Sue, 2007). Lesbian, gay, bisexual, and transgender (LGBT) youth have been identified as one such population (D'Augelli, 2005; Kosciw, Greytak, Bartkiewicz, Boesen, \& Palmer, 2012; Mustanski, Garofalo, Emerson, 2010). As such, the related litertaure is replete with scholarship that has utilized a deficit perspective that frequently mirrors the institutionalized heterosexism, bias, and prejudice seen elsewhere in society (Green, McCollum, \& Hays, 2008; Sue \& Sue, 2007). Much less reflected in the counseling literature is that most LGBT youth will "develop into healthy and functioning adults" (Davis, Williamson, \& Lambie, 2006, p. 128). Arguably, when this incomplete perspective of LGBT youth is viewed through a social justice lens, questions arise about how such could contribute to and perpetuate increased risk for negative outcomes. 
As the field of counselor education has established a strong professional identity grounded in holism, healthy development, and wellness (Chang, Bario Minto, Dixon, Myers, \& Sweeney, 2012), it is unexpected and antithetical that the counseling literature has focused more on the negative factors of LGBT-identified persons' presenting symptoms and their deleterious outcomes than on identifying resiliency factors or protective processes (Crethar, Torres Rivera, \& Nash, 2008; Singh, Hays, \& Watson, 2011). Similarly, it is surprising that there has not been more attention in the counseling literature on systemic interventions designed to proactively and comprehensively serve LGBT youth or their family, friends, and allies (FFA) given the demonstrated value of using an ecological perspective (Bronfenbrenner, 1979, 2005) and the recognition of the vital role of social support for healthy development (Berk, 2000).

This manuscript seeks to address the identified gap by introducing systems theories and examining how they may be applied in work with FFA of LGBT youth. Although many of the interventions identified have been supported in direct work with LGBT youth, this manuscript is focused on interventions that can be directly implemented with FFA. The authors argue that while the interventions discussed have direct benefit for FFA, as part of social change, they also indirectly positively impact the experiences of LGBT youth, as well as others. In this sense, FFA interventions address numerous counselor advocacy competencies listed within the Advocacy Competencies (Lewis et al., 2003) including client empowerment and advocacy, community collaboration, as well as systems advocacy. As all persons are parts of larger systems, although interventions may take place within a smaller family or friendship system, they can have larger effects as these persons bring new knowledge and advocacy skills to other environments in which they are engaged.

For the purposes of this manuscript, we will utilize the definition provided within the Association for Lesbian, Gay, Bisexual, and Transgender Issues in Counseling (ALGBTIC) Competencieis for Counseling Lesbian, Gay, Bisexual, Queer, Questioning, Intersex and Ally Individuals (2013). They identify allies as those including,

friends, family, significant others, colleagues/associates, mentors, those who seek counseling before they identify as allies and may be heterosexual, cisgender, and/or members of the LGBTQIQ Communities (e.g., a Cisgender, Bisexual Woman who is a Transgender Ally), particularly when the individual holds an identity that has traditionally been marginalized in the LGBTQIQ community. As such, this document refers to the identity labels that are selfassumed, rather than externally applied (pp.24).

As such, persons may identify as allies in different ways and across different contexts throughout their lives, but the identity of ally is self-defined. Authors purport that regardless of an individual's personal belifs and prejudices, the identification as ally in some ways serves as a marker of strength in a relationship with LGBT persons, and 
provides fertile working ground to learn and grow in providing social justice and advocacy towards others.

As a result of the application of systems theories in couseling LGBT youth, authors suggest that resultant services can become more holistically grounded and socially just. In this sense, the authors adhere to the definition of social justice as put forth in the advocacy competencies created by the Counselors for Social Justice (CSJ), in that the goal of interventions with FFA of LGBT youth is to facilitate social adjustment and to afford increased positive outcomes for both LGBT youth and the community as a whole (Lewis, Arnold, House, \& Toporek, 2003).

The authors define advocacy in this context similarly to the concept of "advocacy orientation" as expressed by Counselors for Social Justice; this involves both systems changes interventions as well as the implementation of of empowerment strategies in direct counseling (Lewis et al., 2003, pg. 1). As such, couneslors working from an advocacy orientation would both empower LGBT youth, as well as work directly with FFA to ensure that systemic factors that might serve as a barrier to LGBT youth are identified and a plan is created to facilitate systems change to modify the environment for prevention of future concerns.

The strengths-based and nonpathologizing aspects of this approach will be accentuated. Specific systemic interventions will be identified at each level of the environment in which LGBT youth development occurs. These systemic interventions include group work at the micro level, school/agency-family-community partnerships at the meso level, supervision at the exo level, and advocacy at the macro level. In accordance with systems theories, counselors' use of each of these interventions with FFA has the potential transform the social conetxts in which LGBT youth live, and subsequently positively impact their experiences. As a social justice action and an advocacy effort in itself, the manuscript will conclude with suggestions for how counselors may implement these types of interventions with the FFA of LGBT youth.

\section{Systems Theories}

Although often discussed as a single collective entity, there are many different types of systems theories (e.g., strategic, structural, family, general, ecological). Shared across the varied types of systems theories is the belief that individuals may only be understood within an interactive social context (Bronfenbrenner, 2005). Put another way, systems theories suggest that persons are more than their internal experience, and that to understand a person, counselors need to examine the intersection of individuals and their relationships. According to systems theories, it is the collection and accumulation of dynamic interactions that take place between individuals and across nesting levels that ultimately comprise the network that becomes the system itself. For those unfamiliar with the term nesting, a visual metaphor of bowls of increasing size might be beneficial. Nesting refers to the smallest bowl (or level) being surrounded by the next larger, followed by the next larger, and so on. 
Systems theories do not just look at a person as an individual unit responsible for and impacting only self. Instead, systems theories state that to understand a person, you also must understand them in relationship to their family (or other close relationships), their local community, their state (and any influencing issues within; for LGBT youth this would include laws affirming or opposing marriage equity or human rights ordinances including affecutal orientation or gender identity/expression), their nation (e.g., living in a country that penalizes same-sex attraction or contact), and the world as a whole. In addition, chronological time can be seen as another contextual factor impacting a person (e.g., when they grew up or when they accepted thoughts about LGBT identity). Each of these contextual factors are considered nesting variables.

Concurrently, systems theories recognize the interdependence of the individuals and their subsystems within the larger systemic unit and therefore attend to their interelated functions and goals (Bertalanffy, 1968). This psychological and behavioral interconnection is often referred to as wholeness. Persons impact and are impacted by the dynamic relationships with others (e.g., family, friends, coworkers) as well as the context in which they live (e.g., the house, town/city, state, nation, etc., as well as time or generation in which they grew up or currently live).

Systems theories also purport that the system is a nonsummative unit, meaning that the entirity of the system is greater than the sum of its parts. This is another way of saying that a community is made up of more than just people; it is also the interconnected relationships between people and the impact of those relationships on the community as a whole. In order to preserve itself, however, the system develops mechanisms to maintain balance or homeostasis (Berk, 2000; Bertalanffy, 1968). Homeostasis refers to a stable, consistent environment. A thermostat may illustrate: Theromstats monitor temperature and turn on warming or cooling mechanisms to maintain a stable temperature. Similarly, boundaries, roles, and feedback loops within a system serve to enforce the self-regulating rules and objectives of the system, whether overtly (such as laws) or covertly (such as language or nonverbal messages).

Although ACA identifies social justice and advocacy competencies for counselors, to date these have not been positioned or extensively discussed in conjunction with systems theories. Nonetheless, the salience of the person-in-environment is evident across both. For example, just as authors [add references] have argued that an individual client from a marginalized group cannot be fully understood without also considering the culture and community to which the client belongs, so too contend systems theories. While similar to some of the rationales for advocacy that have been put forth (Dixon, Tucker, Clark, 2010; Hays, Dean, \& Chang, 2007; Green, McCollum, \& Hays, 2008), systems theories provide a conceptual grounding as a rationale for how counselors can effectively intervene in these areas and beyond, for client benefit. 


\section{Levels of Ecological Systems}

Urie Bronfenbrenner was a pioneer in the development of systems theories, exploring individuals and their interactions within natural settings, resulting in practical application and contextual relevance (Bronfenbrenner, 2005). Reflecting the seminal principles of systems theories previously described, ecological systems theory (EST; Bronfenbrenner, 1979 , 2005) can be applied to better understand LGBT youth's experiences and to identify potential "points of entry" for intervention (Luke \& Bernard, 2006, p. 286). As systems thinking eschews diagnosis and applies the principle of circular causality (versus viewing interactions as having a single or linear cause), it can be classified as a positive or strengths-based approach to understanding the experiences of LGBT youth (Galassi \& Akos, 2007). This can be connected to advocacy work, which understands that numerous communities, systems, and the larger social and political environemnt can have an influence on clients' level functioning, needs, and future successes.

EST purports that all growth, development, and adaptation takes place within four nested levels. The first level is the microsystem, which consists of the family and others with whom individuals have close relational bonds (Bronfenbrenner, 2005). The second level is called the mesosystem, including interactions between individuals from the microsystem with others in the proximal environment (Bronfenbrenner, 1995, 2005). For LGBT youth, the proximal environment would likely include school, workplace, and/or community organizations. Although LGBT youth oftentimes do not consciously spend time in the third or fourth levels, the exosystem (encompassing the external or distal milieu) and the macrosystem (the larger socio-cultural-political context) can both have a profound impact on the experiences of individuals (Berk, 2000; Bronfenbrenner, 2005), including LGBT youth.

Elsewhere it has been established that LGBT youth are underserved (Jennings, 2014; Luke, Goodrich, \& Scarborough, 2011; Varjas et al., 2006), but using EST (Bronfenbrenner, 2005), it may be suggested that so too are their family, friends, and allies. When counselors and other helping professionals constrain interventions and soley serve LGBT youth within the microsytem, as is the case when services are delivered to individuals exclusively, three additional levels of points of entry are missed (Goodrich \& Luke, 2009; Luke \& Bernard, 2006, Luke \& Goodrich, 2012). This is problemmatic not only because it limits the availability of the protective influence of social support available to LGBT youth across the meso, exo, and macro levels, but it also ignores the systemic relevance of FFA of LGBT youth. This could further perpetuate the oppressive structures and microaggressions found in society, as it does not allow members of LGBT youth's nesting communities to recognize, reformat, and find a voice to support LGBT youth. Therefore, expanding counselors' awareness of additional points of entry for intervention can be seen as a social justice action and advocacy effort in itself. 
Much of the counseling and counselor education literature to date has approached this service-delivery gap as resulting primarily from a deficit in the multicultural competence of the counselor (e.g., Sue \& Sue, 2007), yet it may also reflect a myopic or outdated theoretical framework (Crethar et al., 2008; Singh et al., 2011) that fails to respond to the needs of LGBT youth (Goodrich \& Luke, 2009; Luke \& Goodrich, 2012). Over a decade ago, Stone (2003) argued the need for complex insights and comprehensive strategies for working with sexual minorities. Most counseling interventions are designed to impact the internal thoughts and feelings of clients, as opposed to impacting the interactions between the clients and their families, friends, and allies. Arguably, both are important. The following section reviews the related research to develop a rationale for working with FFA of LGBT youth as an indirect, but nonetheless potent, method of systemic service delivery.

\section{Family, Friends, and Allies}

Research has supported that there are risks for LGBT youth in either coming out or keeping their affectual orientation and/or gender identity/expression private (Goodrich, 2009; Goodrich \& Gilbride, 2010; Goodrich \& Luke, 2015). Although friends are usually the first recipients of LGBT youth disclosure (D'Augelli, 2005), counselors have been encouraged to help LGBT youth identify how and to whom they may safely disclose (Goodrich \& Luke, 2015; Lasser \& Tharinger, 2003). Such systemically attuned counselors understand that family support and acceptance of LGBT youth's identity may provide protection against the negative effects of homophobic harassment and victimization (Hershberger \& D'Augelli, 1995) as well as play significant roles in promoting positive identity development and psychological adjustment (Elizur \& Ziv, 2001; Goodrich, 2009; Goodrich \& Gilbride, 2010; Goodrich, Selig, \& Trahan, 2012). Friend and ally support has also been demonstrated to similarly serve as a protective factor and to increase resiliency and coping for LGBT persons (Kosciw et al., 2012; Scourfield, Roen, \& McDermott, 2008).

Considering the findings from a series of recent studies supporting the impact of linguistic discourse choice on counselor development (Luke \& Goodrich, 2013; Luke \& Gordon, 2011, 2012), communication with FFA may be complex. Counselors who are working with families and friends of LGBT youth may wish to illuminate how language has the potential to invalidate LGBT youth's concerns and be experienced as microaggressions (Sue et al., 2007). Clarke, Kitzinger, and Potter (2004) found that family members who perceive themselves as supportive may use language that minimizes LGBT youth's experiences. A common example of this is pronoun use, wherein we or us, and they or them, may be experienced as judgmental and nonsupportive. Buser, Goodrich, Luke, and Buser (2011) identified that clients' perceptions of counselor sameness appeared to positively impact alliance and therapeutic outcome. Related, authors (Morsillo \& Prilleltensky, 2007; Rolfe, 2005) have suggested that an increased understanding of LGBT youth's lived experiences, including empathic awareness of strengths and struggles, will assist in providing more comprehensive and 
beneficial counseling interventions. It is possible, therefore, that increased awareness of the same in LGBT youth's FFA could increase not only the social support they are able to provide, but also their advocacy and educational efforts within the varied levels of the systems in which LGBT youth develop.

Supporting the positive impact that FFA may have on the ecological system, Jeltova and Fish (2005) described how schools could use both traditional and systemic styles of consultation with families to provide indirect support to LGBT youth. As educational contexts have also successfully implemented intervention efforts that focused on ally development (Elze, 2006; Evans \& Broido, 2005; Ji, 2007; Mahan et al., 2007; Munin \& Speight, 2010; Stotzer, 2009), counselors working with LGBT youth may consider how to extend such systemic interventions into work and community contexts. Rothman, Keyes, and Boehmer (2012) recently documented the relationship between family support and long-term health behaviors in sexual minority adults and recommended that health professionals provide "all parents" (p. 196) with what could be described as a systemic, psycho-educational intervention. Saltzburg (2007) also examined ways in which narrative re-authoring techniques could be used directly to assist families' adjustment during the coming-out process, thereby indirectly positively impacting LGBT youth's later development. For example, the Boat-Storm-Lighthouse Assessment (Sprunk, 2011) may help the counselor develop a sense of how a family conceptualizes their experiences, including their resources and vulnerabilities. Using the findings from this instrument, the counselor may then assist families in re-authoring their stories to focus on their strengths as well as re-narrate experiences that appear problematic or confusing. Counselors may assist families to see the confidence and strength that LGBT youth have found in disclosure or to rally around or support each other in difficult times.

As research has demonstrated that a families' adjustment process (D'Augelli, Grossman, \& Sparks, 2005; Goodrich, 2009; Goodrich \& Gilbride, 2010; Saltzburg, 2004; Trahan Jr., \& Goodrich, 2015) has influence on that of the LGBT youth, counselors should proactively attend to the many experiences and needs of family, friends, and allies from a developmental, systemic perspective (Stone Fish \& Harvey, 2005) and not only focus on that of the LGBT youth. In this way, counselors may also remind LGBT youth of their personal struggles with accepting their new identity and how this may be a developmental process for family members as well. Use of support groups (Gallor, 2006; Phillips \& Ancis, 2008), and educational resources (Phillips \& Ancis, 2008) have been recommended (Goodrich, 2009) as strategies to assist families struggling with an LGBT youth's disclosure of their sexual orientation. Examples include Parents, Families, and Friends of Lesbians and Gays (PFLAG) and affirming religious organizations (such as Dignity USA).

The ultimate goal of any FFA work is to positively shape the overall environment across the micro, meso, exo, and macro levels into a systemic context that supports social justice and healthy growth for all, but especially LGBT youth; this directly relates to the 
previously cited systems change interventions called for in the Advocacy Competencies (Lewis et al., 2003), which should ground our work. The following section will elucidate the ways in which counselors may conceptualize their work with FFA of LGBT youth using EST (Bronfenbrenner, 2005) and then implement counseling interventions across the four levels of the system. These systemic interventions include group work at the micro level, school/agency-family-community partnerships at the meso level, supervision at the exo level, and advocacy at the macro level. Although each intervention is described separately and could be used as a discrete intervention, it is recommended that counselors consider how to incorporate each into their comprehensive work to better respond to the myriad needs of LGBT youth and their FFA.

\section{Micro Level: Group Work}

The Association for Specialists in Group Work (2000) identified four types of groups: task/work, psycho-educational, counseling, and psychotherapy groups. All four types may reflect a systems perspective while being implemented in the micro level of EST (Bronfenbrenner, 2005) and used with not only LGBT youth, but also their FFA (Bowers, 2015). Puglia and Hall (2010) recently discussed how LGBT youth and others could benefit from group intervention. They identified various types of intra- and interpersonal needs that can be explored and addressed through psycho-educational and counseling groups. Scholars have described how group leaders may implement discrete skills in combination across more elaborate group (techniques, interventions, or activities for greater comprehensive and systematic purposes (Schimmel \& Jacobs, 2011). Despite this and the growing literature that identifies how support, universality, and other therapeutic factors associated with group work (Yalom \& Leszcz, 2005) may be particularly salient for LGBT youth (Goodrich \& Luke, 2010; Luke \& Goodrich, 2013; Stone Fish \& Harvey, 2005), there has been little discussion of how counselors of LGBT youth or those working with their families (Bowers, 2015; LaSala, 2000), friends, and allies (Lasser \& Tharinger, 2003) can use group work skills toward this end.

Although the absence in the literature is curious, there is a plethora of research supporting the effectiveness of Gay-Straight Alliances (GSAs). As a specific form of group work, GSAs have increasingly been recognized as effective in providing supportive educational services and affirming interventions in school contexts (Goodenow, Szalacha, \& Westheimer, 2006; Goodrich \& Luke, 2010; Kosciw et. al., 2012). To date, GSAs have primarily been implemented to directly serve LGBT youth and others, but GSAs are being recognized as a means to positively impact LGBT youth's friends and allies as well. For example, Valenti and Campbell (2009) found that GSA advisors often become involved out of a personal connection, but their work has been shown to impact the system beyond the immediate GSA group itself, including a decrease in verbal and physical harassment, an increase in visibility of allies, and a greater sense of school and organizational belonging (Goodenow et al., 2006; Kosciw et al., 2012). Other studies have noted that these benefits are not restricted only to 
students who attend GSA group meetings, suggesting that the protective factors extend across the entire school.

Although no literature could be identified that discussed family and community involvement with GSAs, the authors are anecdotally aware that several exist. For example, Beck, Rausch, and Wood (2014) discussed how school counselor allies and advocates can develop community and parental coalitions aimed to identify, address, and ameliorate "barriers which inhibit student growth" (p. 363), as well as to positively impact the socio-political culture of the school and community. As such, counselors may wish to creatively conceptualize how to translate and apply the ample GSA literature (e.g., Lee, 2002) to work beyond educational settings with families and in vocational, health, or agency contexts where non-supportive social interactions have also been shown to be deleterious for LGBT youth (Smith \& Ingram, 2004). As GSAs and other forms of group work to serve the FFA of LGBT youth have the potential to benefit individual development and promote positive development, social justice, and organizational change (Mallon, 2008) across systems, more research is needed into how counselors may most effectively utilize group skills within systems theories frameworks as an aspect of their group counseling (see Luke, 2013; Rubel \& Okech, 2006).

Luke (2013) applied principles of group systems theory (Agazarian, 2001; Connors \& Caple, 2005) such that the group leader has the option at any point to intervene across the three levels of the group system: the intrapersonal, interpersonal, and whole group. Further, Luke illustrated how many of the basic group leadership skills could function at the different levels. Although Luke did not conceive of this group-skills categorization as specific to work with LGBT persons or their families, counselors working with the FFA of LGBT youth could easily incorporate it to expand positive intervention across group levels. While some authors have suggested that such intervention is beneficial (Goodrich \& Luke, 2011; Rubel \& Okech, 2006), Kline (2003) cautioned that leader overreliance on any one level can compromise the effectiveness of the group. Paralleling this same flexibility across the levels of EST (Bronfenbrenner, 1995, 2005), the following section will describe how counselors may move beyond group work interventions at the micro level with FFA of LGBT youth and extend this work into the meso level.

\section{Meso Level: School/Agency-Family-Community Partnerships}

Applying Bronfenbrenner's $(1995,2005)$ model to working with LGBT youth, the meso level would extend beyond proximal family, close friends, and allies to include more distal stakeholders. Counselors need to be aware of how individuals in the micro level intersect with those in the meso level (Berk, 2000). As an example, counselors may need to be cognizant of how LGBT youth and their FFA interact with religious community leaders or parents of other youth in school. One intervention that has potential benefit within this level is school/agency-family-community (S/A-F-C) partnerships (Christenson \& Sheridan, 2001; Luke, 2008). Originally conceptualized as 
overlapping spheres of interest, S/A-F-C partnerships are two-way interventions that were developed to increase parental involvement in K-12 school systems (Bryan, 2005; Epstein \& Van Voorhis 2010). Although S/A-F-C partnerships have embodied many forms over the past two decades, Taylor and Adelman (2000) identified eight key dimensions in the process of implementing them: the initiators, the scope, the location, the purpose, the incidence and regularity, the governance, the potential impact, and the cohesiveness across participants. These characteristics have been described as reflecting a paradigm shift (Baker, 2001) wherein the experiences and worldview of all participants are explicitly incorporated. Moreover, Epstein and Van Voorhis (2010) have noted that it is not the partnership effort itself, but the frequent interaction and communication across stakeholders that creates a message of value to the student or client. Research has shown that the meso level (e.g., the school) has not always recognized or responded to the neeeds of LGBT youth (Goodrich \& Luke, 2009) nor necessarily valued the experiences and needs of their FFA, therefore S/A-F-C partnerships may offer a structural and systemic way to prevent and ameliorate these situations.

In addition to increasing collaboration across the stakeholder groups involved, research has shown that S/A-F-C partnerships have additional positive outcomes of relevance to counselors working with the FFA of LGBT youth, including increasing student and client resilience (Bryan, 2005) and facilitating social, emotional, and academic development (Epstein \& Van Voorhis, 2010). Of note is that research has consistently demonstrated that S/A-F-C partnerships benefit all persons within the system or subsystem, but for populations that have been historically underrepresented in educational and organizational hierarchies (National Center for Education Statistics, 2011), the positive impact is disproportionately greater (Luke, 2008). Thus, even though much of the research on S/A-F-C partnerships has utilized participant samples that were connected to K-12 schools, there are opportunities for counselors working both inside and outside the school context to develop S/A-F-C partnerships that support student and client wellbeing and work in tandem with organizational missions. Illustrating the systemic nature of the S/A-F-C partnerships as an intervention, research has suggested that much of their benefit comes from the interpersonal connections and collaborative processes that are developed through ongoing partnership practices (Luke, 2008). It is suggested, therefore, that counselors interested in utilizing S/A-F-C partnerships focus most on the forms and functions of interaction between stakeholders and make the communication process one of their main objectives.

The ease of implementing S/A-F-C partnerships may nonetheless be deceptive. Bryan (2005) cautioned that there are myriad socio-cultural-political challenges that can interfere and present "very complex, subtle, and seemingly insurmountable barriers" to the formation of S/A-F-C partnerships (p.221). As is the case with systemic interventions, scholars have suggested that small, sustainable, but comprehensive interventions are more successful (Christenson \& Sheridan, 2001). Accordingly, counselors working with the FFA of LGBT youth may locate and develop opportunities 
to involve stakeholders across the varied spheres of influence and create partnerships at all levels, not just in service delivery. For example, S/A-F-C partnerships may be charged with review of an organization's mission and policies, help to determine new directions and initiatives, and have input into the assessment and analysis of services provided (Luke, 2008). Scholars have suggested that S/A-F-C partnerships that connect work and education settings to families and organizations provide students and clients with positive role models and corrective experiences, as well as providing recognition of the inherent resources and unique assets of each (Baker, 2001; Bryan, 2005; Coyne \& Mazza, 2007). Counselors working with the FFA of LGBT youth may look to PFLAG or other supportive community organizations and services as a place to begin effecting change at the meso level (Goodrich, 2009).

In work on supporting FFA development of trans and gender noncomforming youth, Harper and Singh (2014) challenge counselors to extend the ally development literature beyond "professionals working with LGBTQ individuals" (p.379) and to develop interventions to effect systemic changes. They outline a range of prevention and intervention strategies that can readily be accomlished within S/A-F-C partnerships, including guidelines for initial contact, psychoedcuation, role-play and other experiential learning strategies, as well aas focused advocacy projects. Related, Cooper, Dollarhide, Radcliff, and Gibbs (2014) also discuss how formal systems for consultation and collaboration with familes and community members should be part of a multidisciplinary approach when working across a social justice framework with LGBT youth and their FFA. Although Cooper et al. (2014) do not directly frame their work within S/A-F-C partnerships, they do address many of the same concepts found within S/A-F-C partnerships including the necessity of intentionality, attention to power differentials, and acknowledgement of ideas for adressing barriers to implementation. They note the importance of counselors and other FFA investing "in their own personal development and seek [ing] ways to integrate social justice" (p. 355) across systems.

\section{Exo Level: Supervision}

At the exo level, counselors working with FFA of LGBT youth may utilize systemic interventions to impact the larger or distal milieu (Berk, 2000). Such interventions are typically planned, ongoing in nature, and programmatic in design (Bronfenbrenner, 2005). Counselor supervision is implemented for the simultaneous and iterative purposes of responding to the needs of LGBT youth (Goodrich \& Luke, 2009), while also improving a counselor's effectiveness in working with family, friends, and allies. Accordingly, there is a growing body of work that identifies LGBT-specific supervision models and practices (Goodrich \& Luke, 2011; Luke \& Goodrich, 2012, 2013; Messinger, 2007). In addition to responding to the unique needs of LGBT youth (and other LGBT persons) and their FFA, these models also seek to assist counselors in developing the requisite knowledge, awareness, and skills to do this work (Beck et al., 2014; Luke \& Goodrich, 2009; Sue \& Sue, 2007). Although counselors are expected to integrate ethical knowledge (Kocet, 2006) with appropriate clinical skills into their best 
practice work with diverse clients, many fail to do so (Luke, Goodrich, \& Gilbride, 2013a, 2013b). Counselor supervision is one systemic method to address this, with the potential to impact not only the counselor and LGBT clients at the micro level, but indirectly impact FFA at the exo level and the ethicality of policies and practices at the meso level as well.

Counselor supervision has been described as the signature pedagogy in the preparation and professional development of counselors and other mental health professionals (Shulman, 2005). Okech and Rubel (2007) described how supervisors and supervisees may conceptualize the focus of their work using the tripartite multicultural competence areas of awareness, knowledge, and skills. Extending this to supervision responding to the needs of LGBT youth and other LGBT persons, Goodrich and Luke (2011) and Luke and Goodrich (2012) offered a framework through which supervisors may approach their work. They described possible ways in which these issues might surface in supervision, including situations involving FFA, and offered a variety of strategies to approach them, dependent upon the supervisee level of development, the context of supervision, and the supervisory objectives.

Given that scholars have recognized that counselors may have biases that inhibit their ability to recognize and respond to the needs of LGBT youth (Goodrich \& Luke, 2009, 2010, 2011) and their FFA (Luke et al., 2013a, 2013b), supervision may assist in identifying interfering attitudes and beliefs and support the development of ongoing reflective practice strategies to minimize the interference (Goodrich \& Luke, 2011; Luke \& Goodrich, 2012, 2013). Additionally, recent research has supported counselors' endorsement of supervision as one possible intervention that may be used to expand counselors' knowledge and build their clinical skills in working with LGBT youth and their families, friends, and allies (Luke, Goodrich, \& Scarborough, 2011). Extending this work, Moe, Perera, and Sepulveda (2014) contended that supervision can be used for ally development more broadly as well. Accordingly, the authors believe that counselor supervision offers an ongoing and formalized opportunity to integrate theory and practice in an anti-oppressive praxis that may challenge social injustices and effect change across the meso system. Advocacy initiatives may extend outside of supervision as well and will be described in the next section as a systemic intervention for families, friends, and allies of LGBT youth at the macro level.

\section{Macro Level: Advocacy}

At the macro level, counselor intervention is aimed at impacting the socio-culturalpolitical context of the system (Berk, 2000; Bronfenbrenner, 1995, 2005). Recent social justice scholarship has identified a broad range of advocacy initiatives that may function as this type of systemic intervention (Crethar et al., 2008; Green et al., 2008; Hays et al., 2007; Singh et al., 2011). In a review of the intertwining history and practice of social justice and advocacy within counseling, Kiselica and Robinson (2001) suggested that LGBT youth and others, as well as their FFA, could benefit from more advocacy at 
the macro level. Further, the field has developed counselor competencies in this area (Lewis et al., 2003). As previously noted, some of the advocacy competencies may be addressed at the micro, exo, and meso levels of the system; however, at the macro level, advocacy interventions are designed to specifically uphold, challenge, or change the socio-cultural-political context. In school counseling, this has been described as an ethical mandate to provide culturally responsive leadership, advocacy, collaboration, and systems change (Dixon, Tucker, \& Clark, 2010), and the authors suggest that this obligation extends to counselors working across other organizational contexts as well. Yet, even counselors with high levels of multicultural competence (Sue \& Sue, 2007) and those firmly committed to social justice (Green et al., 2007; Hays et al., 2007) may encounter conflict in the form of organizational policies or practices that could undermine their work with FFA of LGBT youth (Goodrich \& Luke, 2010).

Most advocacy interventions can be grouped into two broad classifications: those focused on leadership and educational objectives and those that more explicitly involve collaboration and systems change. Examples of educationally focused advocacy interventions with FFA of LGBT youth may take numerous forms, but across these they have been found to increase a sense of safety and belonging in system stakeholders (Galassi \& Akos, 2004), including FFA of LGBT youth. Educational advocacy interventions may include the counselors' work promoting increased understanding and awareness of the needs of LGBT youth (Luke \& Goodrich, 2009), distribution of psychoeducational material supporting LGBT youth and their FFA (Goodrich \& Luke, 2015; Harper \& Singh, 2014), supporting FFA access to and organizational collaboration with LGBT youth-supporting services and programs (Graybill, Varjas, Meyers, \& Watson, 2009), and challenging the use of oppressive, homophobic, and heterosexist language and practices (Graybill et al., 2009) in conversational and professional contexts or organizational literature.

Graybill et al. (2009) discussed a variety of content-specific strategies that counselors could use in their work toward collaboration and systems change with LGBT youth, but many of these are applicable as well in work with FFA of LGBT youth outside of an educational setting. These include counselors' facilitating a dialogue and supporting the needs of FFA of LGBT youth (Goodrich \& Luke, 2010); endeavoring to develop, change, and refine policies and practices to better serve the needs of FFA of LGBT youth (Goodrich, Harper, Luke, \& Singh, 2013); connecting FFA working "with" LGBT youth "for" (p. 386) access to the appropriate treatment and standards of care (Harper \& Singh, 2014); and constructing FFA development models that are widely implemented (Elze, 2006; Evans \& Broido, 2005; Goodrich \& Gilbride, 2010). As noted by others, advocacy interventions are designed to effect socio-cultural-political changes and support resiliency in the FFA of LGBT youth (Beck et al., 2014; Singh et al., 2011). 


\section{Conclusion}

As scholars have increasingly recognized the role of strength-based approaches and preventative systemic interventions in work with historically marginalized populations (Green et al., 2008; Hays et al., 2007), there has been more emphasis on how work with FFA may faciliate protective factors and resiliency in LGBT youth. Even so, there is a need for more work in this area. Although the authors were able to identify limited research and conceptual writing that applied elements of systems thinking in work with LGBT youth, none did so comprehensively. Thus, an EST framework was employed to identify points of entry for systemic interventions across the micro, meso, exo, and macro levels (Bronfenbrenner, 2005) of LGBT youth's experiences. Through the use of group work, school/agency-family-community partnerships, supervision, and advocacy, counselors may enhance the scope of their interventions with FFA and thereby positively impact the four nested systems within which LGBT youth's lived experiences take place.

\section{Author contact information}

Kristopher M. Goodrich, PhD., Counselor Education, MSC05-3040

1 University of New Mexico

Albuquerque, NM 87131

Email: kgoodric@unm.edu

\section{References}

Agazarian, A. (2001). A systems-centered approach to inpatient psychotherapy. Philadelphia, PA: Jessica Kingsley.

Association for Specialists in Group Work (ASGW). (2000). ASGW professional standards for the training of group workers. Journal for Specialists in Group Work, 25, 327-342.

Baker, A. J. (2001). Improving parent involvement programs and practices: A qualitative study of parent perceptions. In S. Redding \& L. G. Thomas (Eds.), The community of the school (pp. 121-153). Lincoln, IL: Academic Development Institute.

Beck, M. J., Rausch, M. A., \& Wood, S. M. (2014). Developing fearless school counselor ally and advocate for LGBTQIQ youth: Strategies for preparation programs. Journal of LGBT Issues in Counseling, 8(4), 361-375. doi: 10.1080/15538605.2014.960126

Berk, L. E. (2000). Child Development (5th ed.). Boston, MA: Allyn and Bacon. 
Bertalanffy, K. L. (1968). General system theory: Foundations, development, applications. New York, NY: George Braziller.

Bowers, H. (2015). Groups for couples and families. In K. M. Goodrich \& M. Luke. Group counseling with LGBTQI persons (pp. 113-134). Alexandria, VA: American Counseling Association.

Bronfenbrenner, U. (1979). Contexts of child rearing: Problems and prospects. American Psychologist, 34(10), 844-850. doi: 10.1037/0003-0066X.34.10.844.

Bronfenbrenner, U. (1995). Developmental ecology through space and time: a future perspective. In P. Moen, G. H. Elder, Jr., \& K. Luscher (Eds.), Examining lives in context: Perspectives on the ecology of human development (619-647). Washington, D.C.: American Psychological Association. Retrieved from, http://www.its.dept.uncg.edu/hdf/facultystaff/Tudge/Bronfenbrenner\%201995.pdf

Bronfenbrenner, U. (2005). Making human beings human: Bioecological perspectives on human development. Thousand Oaks, CA: Sage Publications.

Bryan, J. A. (2005). Fostering educational resilience and achievement in urban schools through school-family-community partnerships. Professional School Counseling, 8, 219-227.

Buser, J., Goodrich, K. M., Luke, M., Buser, T. (2011). A narratology of lesbian, gay, bisexual, and transgender clients' experiences addressing religious and spiritual issues in counseling. The Journal of LGBT Issues in Counseling, 5(3-4), 282-303.

Chang, C. Y., Bario Minto, C. A., Dixon, A. L., Myers, J. E., \& Sweeney, T. J. (2012). Professional counseling excellence through leadership and advocacy. New York, NY: Routledge.

Christenson, S. L., \& Sheridan, S. M. (2001). Schools and families: Creating essential connections for learning. New York, NY: The Guilford.

Clarke, V., Kitzinger, C., \& Potter, J. (2004). 'Kids are just cruel anyway': Lesbian and gay parents' talk about homophobic bullying. British Journal of Social Psychology, 43, 521550.

Connors, J. V., \& Caple, R. B. (2005). A review of group systems theory. Journal for Specialists in Group Work, 30, 93-100.

Cooper, J. M., Dollarhide, C. T., Radcliff, K. M., \& Gibbs, T. A. (2014). No lone wolf: A multidisciplinary approach to creating safe schools for LGBT youth through the development of allies. Journal of LGBT Issues in Counseling, 8(4), 344-360. doi: 10.1080/15538605.2014.960128.

Coyne, R. K., \& Mazza, T. (2007). Ecological group work applied to schools. The Journal for Specialists in Group Work, 32(1), 19-29. 
Crethar, H., Torres Rivera, E., \& Nash, S. (2008). In search of common threads: Linking multicultural, feminist, and social justice paradigms. Journal of Counseling \& Development, 86, 269-278.

D'Augelli, A. R. (2005). Stress and adaptation among families of lesbian, gay, and bisexual youth: Research challenges. Journal of GLBT Family Studies, 1(2), 115-136.

D'Augelli, A. R., Grossman, A. H., \& Sparks, M. T. (2005). Parents' awareness of lesbian, gay and bisexual youths' sexual orientation. Journal of Marriage and Family, 67, 474-482.

Davis, K. M., Williamson, L. L., \& Lambie, G. W. (2006). Sexual minority adolescents. Journal of LGBT Issues in Counseling, 1(1), 127-140.

Dixon, A. L., Tucker, C., Clark, M. A. (2010). Integrating social justice advocacy with national standards of practice: Implications for school counselor education. Counselor Education and Supervision, 50, 103-115.

Elizur, Y., \& Ziv, M. (2001). Family support and acceptance, gay male identity formation, and psychological adjustment: A path model. Family Process, 40, 125-144.

Elze, D. E. (2006). Working with gay, lesbian, bisexual, and transgender students. In C. Franklin, M. B. Harris, \& P. Allen-Meares (Eds.). The school services sourcebook: A guide for school- based professionals (pp. 861-870). New York, NY: Oxford University Press.

Epstein, J. L., \& Van Voorhis, F. L. (2010). School counselors' roles in developing partnerships with families and communities for student success. Professional School Counseling, 14(1), 1-14.

Evans, N. J., \& Broido, E. M. (2005). Encouraging the development of social justice attitudes and actions in heterosexual students. New Directions for Student Services, 110, 43-54.

Galassi, J. P., \& Akos, P. (2004). Developmental advocacy: Twenty-first century school counseling. Journal of Counseling \& Development, 82(2), 146-157.

Galassi, J. P., \& Akos, P. (2007). Strengths-based school counseling: Promoting student development and achievement. Mahwah, NJ: Lawrence Erlbaum Associates.

Gallor, S. M. (2006). Heterosexual parents' gender role attitudes, religious orientation, heterosexist beliefs, support group experiences, and relationship functioning with their lesbian and gay children. (Doctoral dissertation, University of Maryland, College Park, 2006). Retrieved on July 23, 2013 from https://drum.umd.edu/dspace/bitstream/1903/3838/1/umi-umd-3683.pdf

Goodenow, C., Szalacha, L., \& Westheimer, K. (2006). School support groups, other school factors, and the safety of sexual minority adolescents. Psychology in the Schools, 43, 573-589. 
Goodrich, K. M. (2009). Mom and dad come out: The process of identifying as a heterosexual parent with a lesbian, gay, or bisexual child. Journal of LGBT Issues in Counseling, 3(1), 37-61.

Goodrich, K. M., \& Gilbride, D. D. (2010). The refinement and validation of a model of family functioning after child's disclosure as lesbian, gay or bisexual. Journal of LGBT Issues in Counseling, 4(2), 92-121.

Goodrich, K. M., Harper, A., Luke, M., \& Singh, A. A. (2013). Best practices for school counselors working with LGBTQ youth. The Journal of LGBT Issues in Counseling, 7(4), 307-322. doi: 10.1080/ 15538605. 2013.83933.

Goodrich, K. M., \& Luke, M. (2009). LGBTQ responsive school counseling. Journal of LGBT Issues in Counseling, 3(2), 113-127.

Goodrich, K. M., \& Luke, M. (2010). Experiences of school counselors-in-training in group work with LGBTQ adolescents. The Journal for Specialists in Group Work, 35(2), 143-159.

Goodrich, K. M., \& Luke, M. (2011). The LGBTQ responsive model for supervision of group work. Journal for Specialists in Group Work, 36(1), 22-40.

Goodrich, K. M., \& Luke, M. (2015). Group counseling with LGBTQI persons. Alexandria, VA: American Counseling Association.

Goodrich, K. M., Selig, J. P., \& Trahan, D. P., Jr. (2012). The Self-Report Family Inventory (SFI): An exploratory factor analysis. Measurement and Evaluation in Counseling and Development, 45(4), 245-256.

Graybill, E. C., Varjas, K., Meyers, J., \& Watson, L. B. (2009). Content-specific strategies to advocate for lesbian, gay, bisexual, and transgender youth: An exploratory study. School Psychology Review, 38(4), 570-584.

Green, E. J., McCollum, V. C., \& Hays, D. G. (2008). Teaching advocacy counseling: A social justice paradigm of awareness, knowledge and skills. Journal for Social Action in Counseling and Psychology, 1(2), 14-29.

Harper, A., \& Singh, A. (2014). Supporting ally development with families of trans and gender nonconforming (TGNC) youth. Journal of LGBT Issues in Counseling, 8(4), 376-388. doi: 10.1080/15538605.2014.960127.

Hays, D. G., Dean, J. K., \& Chang, C. Y. (2007). Addressing privilege and oppression in counselor training and practice: A qualitative analysis. Journal for Counseling and Development, 85, 317-324.

Hershberger, S. L., \& D'Augelli, A. R. (1995). The impact of victimization on the mental health and suicidality of lesbian, gay, and bisexual youths. Developmental Psychology, 31, 6574. 
Jeltova, I., \& Fish, M. C. (2005). Creating school environments responsive to gay, lesbian, bisexual, and transgender families: Traditional and systemic approaches for consultation. Journal of Educational and Psychological Consultation, 16(1\&2), 17-33.

Ji, P. (2007). Being a heterosexual ally to the lesbian, gay, bisexual, and transgendered community: Reflections and development. Journal of Gay \& Lesbian Psychotherapy, 11(3/4), 173-185.

Kiselica, M. S. \& Robinson, M. (2001). Bringing advocacy counseling to life: The history, issues, and human dramas of social justice work in counseling. Journal of Counseling \& Development, 79, 387-397.

Kline, W. B. (2003). Interactive group counseling and therapy. Saddle River, NJ: Prentice Hall.

Kocet, M. M. (2006). Ethical challenges in a complex world: Highlights of the 2005 ACA code of ethics. Journal of Counseling and Development, 84(2), 228-234.

Kosciw, J. G., Greytak, E. A., Bartkiewicz, M. J., Boesen, M. J., \& Palmer, N. A. (2012). The 2011 National School Climate Survey: Experiences of lesbian, gay, bisexual and transgender youth in our nation's schools. New York, NY: Gay, Lesbian and Straight Education Network.

LaSala, M. C. (2000). Gay male couples: The importance of coming out and being out to parents. Journal of Homosexuality, 39, 47-71.

Lasser, J., \& Tharinger, D. (2003). Visibility management in school and beyond: A qualitative study of gay, lesbian, bisexual youth. Journal of Adolescence, 26, 233-244.

Lee, C. (2002). The impact of belong to a high school Gay/Straight Alliance. The High School Journal, 85, 13-26.

Lewis, J., Arnold, M. S., House, R., \& Toporek, R. (2003). ACA Advocacy Competencies. Retrieved online from, http://counseling.org/Publications

Luke, M. (2008). School-family-community partnerships: Implications for school counselors to bridge the gap in urban schools. New York State School Counseling Journal, 5(2), 13-22.

Luke. M. (2013). Effective group leadership interventions. In J. L. Delucia-Waack, C. L. Kalonder, \& M. T. Riva (Eds.), Handbook of group counseling and psychotherapy (2nd ed.) (pp. 107-120). Thousands Oak, CA: Sage.

Luke, M., \& Bernard, J. M. (2006). The school counseling supervision model: An extension of the Discrimination Model. Counselor Education and Supervision, 45, 282-295.

Luke, M., \& Goodrich, K. M. (2009). School counseling for LGBTQ students: Expanding school counselors' knowledge, awareness, and skills. New York State School Counseling Journal, 6(2), 44-47. 
Luke, M., \& Goodrich, K. M. (2012). LGBTQ responsive school counseling supervision. The Clinical Supervisor, 31(1), 81-102. doi:10.1080/07325223.2012.672391.

Luke, M., \& Goodrich, K. M. (2013). Investigating the LGBTQ responsive model of group supervision. Journal for Specialists in Group Work, 38(2), 121-145.

Luke, M., Goodrich, K. M., \& Gilbride, D. D. (2013a). Intercultural model of ethical decisionmaking: Addressing worldview dilemmas in school counseling. Counseling and Values Journal, 58(2), 177-194.

Luke, M., Goodrich, K. M., \& Gilbride, D. (2013b). Testing the intercultural model of ethical decision making with counselors-in-training. Counselor Education and Supervision, 52, 222-234.

Luke, M., Goodrich, K. M., \& Scarborough, J. L. (2011). Integration of K-12 LGBTQI student population into school counselor education curricula: The current state of affairs. Journal of LGBT Issues in Counseling, 5(2), 80-101. DOI: 10.1080/15538605.2011.574530

Luke, M., \& Gordon, C. (2011). A discourse analysis of school counseling supervisory email. Counselor Education and Supervision, 50, 274-291.

Luke, M., \& Gordon, C. M. (2012). Supervisors' use of reinforcement, reframing, and advice to re-author the supervisory narrative through email supervision. The Clinical Supervisor, 31(2), 159-177. doi:10.1080/07325223.2013.730020.

Mahan, W. C., Varjas, K., Dew, B., Meyers, J., Singh, A. A., Marshall, M. L., \& Graybill, E. C. (2007). School and community service providers' perspectives on gay, lesbian, and questioning bullying. Journal of LGBT Issues in Counseling, 1(2), 45-66.

Mallon, G. P. (Ed.). (2008). Social work practice with lesbian, gay, bisexual, and transgender people (2nd ed.). New York, NY: Routledge.

Messinger, L. (2007). Supervision of lesbian, gay, and bisexual social work students by heterosexual field instructors: A qualitative dyad analysis. The Clinical Supervisor, 26, 195-222.

Moe, J. L., Perara-Diltz, D., \& Sepulveda, V. (2014). Beyond competence: Fostering LGBTQQI ally development through supervision. Journal of LGBT Issues in Counseling, 8(4), 389401. doi: $10.1080 / 15538605.2014 .960129$

Morsillo, J., \& Prilleltensky, I. (2007). Social action with youth: Interventions, evaluation, and psychopolitical validity. Journal of Community Psychology, 35, 325-340.

Munin, A., \& Speight, S. L. (2010). Factors influencing ally development of college students. Equity \& Excellence in Education, 42(2), 249-264. 
Mustanski, B. S., Garofalo, R., \& Emerson, E. M. (2010). Mental health disorders, psychological distress, and suicidality in a diverse sample of lesbian, gay, bisexual, and transgender youths. American Journal of Public Health, 100(12), 2426-2432.

National Center for Educational Statistics (2011). The condition of education 2011, U.S. Department of Education. Retrieved on July 16, 2013, from http://nces.ed.gov/pubs2011/2011033.pdf

Okech, J. E. A., \& Rubel, D. (2007). Diversity competent group work supervision: An application of the supervision of group work model (SGW). The Journal for Specialists in Group Work, 32, 245-266.

Phillips, M. J., \& Ancis, J. R. (2008). The process of identity development as the parent of a lesbian or gay male. Journal of LGBT Issues in Counseling, 2(2), 126-158.

Puglia, B., \& Hall, S. F. (2010). Group work: Gay, lesbian, and bisexual clients. In D. Capuzzi, D. R. Gross, \& M. D. Stauffer (Eds.), Introduction to group work (5th ed.) (pp. 537-566). Denver, CO: Love Publishing Company.

Rothman, E. F., Keyes, S., \& Boehmer, U. (2012). Parents' supportive reactions to sexual orientation disclosure associated with better health: Results from a population-based survey of LGB adults in Massachusetts. Journal of Homosexuality, 59(2), 186-200.

Rubel, D., \& Okech, J. (2006). The supervision of group work model: Adapting the discrimination model for supervision of group workers. Journal for Specialists in Group Work, 31, 113-134.

Saltzburg, S. (2004). Learning that an adolescent child is gay or lesbian: The parent experience. Social Work, 49, 109-118.

Saltzburg, S. (2007). Narrative therapy pathways for re-authoring with parents of adolescents coming-out lesbian, gay, and bisexual. Contemporary Family Therapy, 29(1-2), 57-69.

Schimmel, C. J., \& Jacobs, E. E. (2011). When leaders are challenged: Dealing with involuntary members in groups. Journal for Specialists in Group Work, 36(2), 144-158.

Scourfield J, Roen K, McDermott L. (2008). Lesbian, gay, bisexual and transgender young people's experiences of distress: Resilience, ambivalence and self-destructive behaviour. Health and Social Care in the Community, 16(3):329-336.

Shulman, L. (2005). The signature pedagogies of the professions of law, medicine, engineering and the clergy: Potential lessons for the education of teachers. Paper presented at the Math Science Partnerships (MSP) Workshop: "Teacher education for effective teaching and learning," hosted by the National Research Council's Center for Education. Irvine, CA. Retrieved from http://hub.mspnet.org/media/data/ Shulman_Signature_Pedagogies.pdf?media_000000001297.pdf 
Singh, A. A., Hays, D. G., \& Watson, L. S. (2011). Strength in the face of adversity: Resilience strategies of transgender individuals. Journal of Counseling \& Development, 89(1), 2027.

Smith, N. G., \& Ingram, K. M. (2004). Work-place heterosexism and adjustment among lesbian, gay, and bisexual individuals: The role of unsupportive social interactions. Journal of Counseling Psychology, 51(1), 57-67.

Sprunk, T. P. (2011). The Boat-Lighthouse-Tree Assessment. In L. Lowenstein (Ed.), Favorite therapeutic activities for children, adolescents, and families: Practitioners share their most effective interventions. (pp. 4-5). Toronto, Canada: Champion Press.

Stone, C. B. (2003). Counselors as advocates for gay, lesbian, and bisexual youth: A call for equity and action. Multicultural Counseling and Development, 31, 143-155.

Stone Fish, L., \& Harvey, R. G. (2005). Nurturing queer youth. New York, NY: W.W. Norton \& Company.

Stotzer, R. L. (2009). Straight allies: Supportive attitudes toward lesbians, gay men, and bisexuals in a college sample. Sex Roles, 60, 67-80.

Sue, D. W., Capodilupo, C. M., Torino, G. C., Bucceri, J. M., Holder, A. M. B., Nadal, K. L., \& Esquilin, M. (2007). Racial microaggressions in everyday life: Implications for clinical practice. American Psychologist, 62, 271-286. doi:10.1037/0003-066X.62.4.271

Sue, D. W., \& Sue, D. (2007). Counseling the culturally diverse: Theory and practice (5th ed.). New York, NY: Wiley, John \& Sons, Inc.

Taylor, L. \& Adelman, H. S. (2000). Connecting schools, families, and communities. Professional School Counseling, 3, 298-301.

Trahan, Jr., D. P., \& Goodrich, K. M. (2015). You think you know me, but you have no idea: Dynamics in African American families following a son's or daughter's disclosure as LGBT. The Family Journal, 23, 147-157.

Valenti, M., \& Campbell, R. (2009). Working with youth on LGBT issues: Why Gay-Straight Alliance advisors become involved. Journal of Community Psychology, 37(2), 228-248. doi:10.1002/jcop.20290.

Varjas, K., Mahan, W. C., Meyers, J., Birckbichler, L., Lopp, G., \& Dew, B. J. (2006). Assessing school climate among sexual minority high school students. Journal of LGBT Issues in Counseling, 1(3), 49-75.

Yalom, I. D., \& Leszcz, M. (2005). The theory and practice of group psychotherapy (5th ed.). New York, NY: Basic Books. 